\title{
AC 2010-651: IMPROVING LEARNING OUTCOMES IN ENGINEERING EDUCATION: STUDENT RETENTION AND QUALITY
}

\section{Jean-Claude Thomassian, State University of New York, Maritime College}

Dr. Jean-Claude Thomassian received his BS degrees in Electrical Engineering and Mechanical Engineering from the University of Toledo in 1992 and 1993, respectively, and MS and Ph.D. degrees in Electrical Engineering from The University of Toledo in 1995 and 2002. His main professional interests are in mixed mode IC design and electrical engineering education; his recent research activity concentrates on symbolic analysis of circuits and MOS models.

\section{Anoop Desai, Georgia Southern University}

Dr. Anoop Desai received his BS degree in Production Engineering from the University of Bombay in 1999, and MS and Ph.D. degrees in Industrial Engineering from The University of Cincinnati in 2002 and 2006. His main research interests are in Product Lifecycle Management, Design for the Environment, Total Quality Management including tools for Six Sigma and Ergonomics. 


\title{
Improving Learning Outcomes in Engineering Education: Student Retention and Quality
}

\begin{abstract}
This paper discusses the use of Media Based Instruction method as an educational effort to improve student retention and quality in an introductory Electronics and Network Analysis course offered at a university in northeastern United States. It also seeks to study the effects of technology-based instruction that complements conventional instruction. This progress, as well as lessons learned in the first three years of Media Based Instruction in introductory engineering courses (namely Circuits, Electronics, Network Analysis, and C++ for Digital Computations) is evaluated with data. The efficacy of embedding conventional teaching with Media Based Instruction is assessed.
\end{abstract}

\section{Introduction}

This paper explores the results of a study and feedback completed by students. The feedback was based on their outlook toward a media-based tool that was used in the instruction of Electronics and Network Analysis. It also seeks to present an educational effort to improve students' retention and quality by engaging students in their studies. Our evaluation complements other studies on media-based instruction and student engagement. Cohen et $\mathrm{al}^{1}$ found that students learned more from such instruction modes compared to conventional modes of instruction. Powell et $\mathrm{al}^{2}$ also explored this topic and found that such instructional modes had the effect of raising the GPAs of the students. Furthermore, Chen et $\mathrm{al}^{3}$ found that enhancing student engagement is an essential approach for improving student retention, success and outcomes.

A midterm project was assigned where the class was randomly divided by the professor into several groups (3-4 students per group). They had to build a night lamp given some specifications, write a report, and give a 5-10 minute Powerpoint presentation. This exercise fostered a collaborative learning environment that facilitated student engagement where learning is active and interactive amongst themselves, their peers, and their professors inside and outside of the classroom.

PSpice, Personal Simulation Program with Integrated Circuit Emphasis, is a general purpose analog circuit and digital logic simulation software used to check the reliability of circuit designs and to predict circuit behavior. $\mathrm{SPICE}^{4}$ was originally developed at the Electronics Research Laboratory of the University of California at Berkeley. PSpice is a commercial version of SPICE and is now owned by Cadence Design Systems. Supplementary information about PSpice is available at: http://www.cadence.com/products/orcad/pages/default.aspx.

\section{Electronics and Network Analysis: Course Outline}

The electronics course deals with an introduction to electronic devices and their applications. 
The course covers an introduction to the physical operation of semiconductor devices. The basic electronic semiconductor devices such as the diode, the field-effect transistor, and the bipolar junction transistor are studied. Device models are developed to aid in circuit analysis and design. Biasing, small-signal and large signal analysis and the principles employed in the design of electronic circuits are included in the course. Students also gain experience applying PSpice to electronic design and visualization. Circuit Analysis is a pre-requisite course. Mostly students from the electrical engineering program enroll in this course, as it is a required course for their major. This course is a four credit hour course (two 75 minutes combined with a three hour laboratory meeting each week). A pilot study was conducted for this course. The objective of this course was to develop the following skills in students completing the course:

1. Analyze circuits containing electronic devices using suitable models ${ }^{5-7}$.

2. Analyze linear circuits containing operational amplifiers ${ }^{5-7}$.

3. Design circuits containing electronic devices to control signals ${ }^{5-7}$.

4. Use PSpice to design and analyze electronic circuits.

Network Analysis deals with a general introduction to elementary rules, theorems, and laws applicable to AC circuits. The course includes an introduction to differential equation modeling and analysis of linear circuits with sinusoidal inputs (power, phasors, impedances, and admittances). A complete treatment of circuit analysis in the frequency domain (Bode plots, frequency response, Laplace transforms, and Fourier analysis) is included. Laboratory work emphasizes frequency response, circuit synthesis, and PSpice simulation/modeling. This includes building and testing circuits to show and support theoretical concepts. Differential Equations and Circuit Analysis are prerequisite courses. Mostly students from the electrical, mechanical, navel architecture, marine engineering programs enroll in this course. This course is a required course for the electrical and marine engineering majors. It is a three credit hour course (a two hour combined with a two hour laboratory meeting each week). A pilot study was conducted for this course. The objective of this course was to develop the following skills in students completing the course:

1. Develop models of circuits in terms of differential equations ${ }^{8-11}$.

2. Analyze circuits containing resistors, capacitors, inductors and op-amps driven by sinusoidal inputs by using the concepts of phasors, impedances, admittances and compute power ${ }^{8-11}$.

3. Use Laplace transforms for the analysis of circuits in the s-domain including Bode plots and frequency response. Also, perform Fourier circuit analysis ${ }^{8-11}$.

4. Use PSpice to simulate and analyze simple electronic circuits.

The abovementioned courses have a laboratory component where students build simple electric circuits and make measurements in the laboratory by using basic laboratory equipment, computer simulation tools, and work in teams.

The course objectives are in agreement with ABET Criterion 3 outcome and assessment for accrediting Engineering programs ${ }^{12}$. 


\section{Assessment Method and Information Gathering}

The next sections of the paper report the outcomes and feedback of a survey that the students completed. These studies were based on their outlook on the media based tutorial that was used in the instruction in order to ease the instruction of Electronics and Network Analysis course. The tutorials were used to complement conventional mode of instruction and to help student insight of engineering fundamentals. These tutorials also provide an effective interactive learning environment where they can get instant feedback to what-if questions.

\section{Student Population}

Twenty-three students at a university in northeastern United States participated in the study. Eleven of these students were enrolled in Electronics and twelve were in enrolled in Network Analysis. $70 \%$ of the participants were junior and $30 \%$ were senior. Students varied in age from 20 to 32 years with an average student age of approximately 23 years old. Students ranked themselves regarding computer skills based on a 10-point scale, 10 being the highest. Of the 23 respondents, $74 \%$ thought their level of computer skills to be 7 or higher and $26 \%$ below 7 . Based on gender, there were $91 \%$ male and $9 \%$ female respondents.

\section{Technology Based Tutorial for Instructing Engineering Fundamentals}

A novel media based tutorial was developed to facilitate teaching engineering fundamentals and PSpice for Electronics and Network Analysis course. Students enrolled in the course had access to the media-based tutorial which was housed on a network drive. To gain access to the modules, they had to use a campus computer to log onto their accounts. The tutorial starts by giving a stepby-step simulated instruction to learn some of the basic procedures of using PSpice - analysis of a resistive circuit, DC, AC, and Transient analysis.

The tutorial explains all the fundamental setups, file saving, operating the program, and viewing the results through text editor and screen captures. All the main points are shown in full detail. Students can go through the tutorial at their own pace, time, and are not under any time constraint or rush to complete the tutorials.

\section{Evaluation Procedure}

Students were asked to log on to their campus account and download the tutorial from a specified folder on a network drive. The majority of the students had never been exposed to PSpice at the time of the performance of this media-based tutorial. They were able to follow and understand the tutorial with relative ease and in a little amount of time. In the following laboratory session they used PSpice to run a simulation to analyze the given laboratory that was due for that day.

The main evaluation objective was to evaluate students' outlook to media based tutorials. To achieve this, a questionnaire consisting of 12 questions was given to students enrolled in Electronics and Network Analysis at the end of the laboratory session. The full survey used in this study consisted of 12 question regarding media based instruction using a 5 point Likert scale (1=strongly disagree; $2=$ disagree; $3=$ neutral; 4=agree; 5=strongly agree) and an additional 
question on self assessment of computer skills. In addition, background information consisting of the students major, year in college, age, and gender was collected. Students were asked to write comments regarding the use of media based tutorials on the back of the questionnaire.

\section{Statistical Results and Analysis}

Statistical results from the 23 participants are presented in Table 1. The group average scores for all questions are markedly above 3.0. This result indicates that as a whole, students either strongly agree or agree to all statements which indicate that they have favorable attitudes towards media based tutorials. Comparing average scores across respondents shows that the majority of students have positive responses.

While we did not have adequate data points to provide consistent results, the table serves to convey similarities and differences in the attitudes of students. In general, the majority of students agree on most of the questions. However, there were a few questions which did not follow the same pattern. For example, for question 7, only $40 \%$ of the respondents thought that they prefer learning by traditional textbook methods instead of technology-based instruction modules. For question 9, 30\% of student respondents thought that the conventional mode of instruction does a mediocre job when dealing with learning CAD tools. Taken together, these imply that the students prefer a supplementary mode of instruction to conventional lectures.

\section{Table 1: Summary of Survey Responses}

\begin{tabular}{|c|c|c|}
\hline Question & Mean & $\begin{array}{l}\text { Proportion that } \\
\text { Agrees or } \\
\text { Strongly Agrees }\end{array}$ \\
\hline $\begin{array}{l}\text { 1. I am highly conversant with using a wide array of computing applications such as } \\
\text { MS Office. }\end{array}$ & 4.3 & $80 \%$ \\
\hline $\begin{array}{l}\text { 2. I feel technology driven instruction techniques facilitate ease of learning CAD } \\
\text { tools such as PSpice. }\end{array}$ & 3.9 & $80 \%$ \\
\hline $\begin{array}{l}\text { 3. I would prefer to use technology based instruction techniques while learning to } \\
\text { use PSpice when I practice by myself. }\end{array}$ & 3.7 & $70 \%$ \\
\hline $\begin{array}{l}\text { 4. Technology driven instruction plays a paramount role in making learning } \\
\text { enjoyable. }\end{array}$ & 3.6 & $70 \%$ \\
\hline 5. I think learning CAD tools such as PSpice will be beneficial to my prospects. & 4.3 & $100 \%$ \\
\hline 6. I feel technology related instructional materials are easy to understand. & 4.1 & $70 \%$ \\
\hline $\begin{array}{l}\text { 7. Technology based instruction techniques are more helpful than textbooks in the } \\
\text { learning process. }\end{array}$ & 3.3 & $40 \%$ \\
\hline $\begin{array}{l}\text { 8. Technology based instruction techniques are intriguing and help me concentrate } \\
\text { on the subject matter better than other techniques. }\end{array}$ & 3.6 & $60 \%$ \\
\hline $\begin{array}{l}\text { 9. Traditional methods do a mediocre job when dealing with learning CAD tools } \\
\text { such as PSpice. }\end{array}$ & 3.2 & $30 \%$ \\
\hline $\begin{array}{l}\text { 10. I can learn in an unhurried manner and pace myself using technology based } \\
\text { instruction techniques. }\end{array}$ & 3.8 & $60 \%$ \\
\hline $\begin{array}{l}\text { 11. Technology based instruction techniques get me more involved in the subject } \\
\text { matter. }\end{array}$ & 3.6 & $60 \%$ \\
\hline $\begin{array}{l}\text { 12. I was encouraged to experiment and learn more due to technology based } \\
\text { instruction. }\end{array}$ & 3.7 & $60 \%$ \\
\hline
\end{tabular}




\section{Student Comments}

Below are actual comments by the participants. They provide reactions of the students to mediabased instruction in more detail.

- "PSpice allows us to quickly glean a broad range of data from a circuit, providing much more in-depth familiarity with its function. Traditional pen and paper analysis simply cannot compare in that respect."

- "PSpice is nice, but when you get an error message \& you can't understand what you did wrong it can be a real hassle. I still feel practice with the instructor, and then yourself, is the best, technology-related or otherwise."

- "Technology is a good aid to instruction but I prefer traditional lecture/HW."

- "The tutorials were easy to follow, and made the labs much easier to complete."

- "Found the tutorials to very helpful w/the lab assignments."

- "People learn better different ways. It would be foolhardy to completely abandon traditional teaching styles, but at the same time using CACs or Pspice can help students understand the material better. In the end, I feel person to person interaction is a vital step in the learning process."

- "With regards to the technology based approach, which I connot agree more with the fact that they help, especially when learning to operate CAD software such as pspice, they make the doing so much easier ..."

- "Pspice was fun to learn using the tutorials."

\section{Conclusion}

This paper presented the results of a questionnaire taken in order to measure the effectiveness of technology-based teaching methods in electronics and network analysis course offered at a university in northeastern United States. From this study, it is concluded that students prefer traditional mode of instruction complemented by media based instruction to facilitate the learning of engineering fundamentals with minimal time. The authors intend to repeat this experiment over another several years. Experimental results will be shared with the academic community in the future through appropriate publications.

\section{References}

1. P. Cohen, B. Ebeling and H. Kulik, "A meta-analysis of outcomes studies of visual-based instruction," Educational Communications and Technology Journal, vol. 29, no. 1, pp.26-36, March, 1981.

2. J.V. Powell, V.G. Aeby Jr. and T. Carpenter-Aeby, "A comparison of student outcomes with and without teacher facilitated computer-based instruction," Computers \& Education, vol. 40, no. 2, pp. 183-191, February, 2003.

3. H. L. Chen, L. R. Lattuca and E. R. Hamilton, "Conceptualizing engagement: Contributions of faculty to Student Engagement in Engineering,” Journal of Engineering Education, vol. 97, no. 3, pp. 339-353, July 2008.

4. L. W. Nagel, "SPICE2: A Computer Program to Simulate Semiconductor Circuits." Tech. Rep. UCB/ERL M520, University of California, Berkeley, 1975 
5. A. S. Sedra and K. C. Smith, Microelectronic Circuits, 5th ed., Oxford University Press, 2004.

6. F. Horowitz and W. Hill, The Art of Electronics, 2nd ed., Cambridge University Press, NY, 1989.

7. A. R. Hambley, Electronics, 4th ed., Prentice-Hall, Upper Saddle River, NJ, 2008.

8. W. D. Stanley, Network Analysis with Applications, 4th ed., Prentice Hall, 2003.

9. C. K. Alexander and M. N. O. Sadiku, Fundamentals of Electric Circuits, 4th ed., McGraw-Hill, 2008.

10. M. Arshad, Network Analysis and Circuits, Infinity Science Press, 2008.

11. J. W. Nilsson and S. Riedel, Electric Circuits, 8th ed., Prentice Hall, 2008.

12. ABET, "Criteria for Accrediting Engineering Programs", ABET, Inc., 2010. 